\title{
Applications, Issues and Futures of Nanofiltration for Drinking Water Treatment
}

\author{
Mohammad Ali Zazouli ${ }^{1}$; Edris Bazrafshan ${ }^{2, *}$ \\ ${ }_{1}^{1}$ Department of Environmental Health Engineering, Health Sciences Research Center, Faculty of Health, Mazandaran University of Medical Sciences, Sari, IR Iran \\ ${ }^{2}$ Health Promotion Research Center, Zahedan University of Medical Sciences, Zahedan, IR Iran \\ ${ }^{*}$ Corresponding author: Edris Bazrafshan, Health Promotion Research Center, Zahedan University of Medical Sciences, Zahedan, IR Iran. Tel: +98-5413425829, Fax: +98-5412420014, \\ E-mail:Ed_bazrafshan@yahoo.com
}

Received: January 23, 2015; Accepted: March 12, 2015

Keywords: Water Purification; Water Treatment; Membrane Process; Water Pollution

\section{Definition and Classifications}

Membrane process has been increasingly used in water and wastewater treatment, because these processes can successfully produce water of superior quality compared to conventional processes $(1,2)$. The pressure-driven membranes are classified to four types: microfiltration (MF), ultrafiltration (UF), nanofiltration (NF), and reverse osmosis (RO). The word NF was defined because its separation cutoff size was in the $1 \mathrm{~nm}$ range (3). Water passing through the membrane is called permeates, while the remaining water is called concentrate or retentate. Permeate is relatively free of targeted dissolved solutes, which in RO and NF is free of ions such as sodium, chloride, calcium or magnesium, and dissolved natural organic matter $(\mathrm{NOM})(2,3)$.

\section{Applications}

In recent years, membrane processes such as NF membranes have been widely recognized as the best technologies for water treatment (4). The primary goal of NF membranes is to use it for water softening, desalinate brackish waters, and reduce disinfection by-product (DBP) precursors. Other objectives including advanced treatment for water reuse, NOM (5), the rejection of pharmaceutically active compounds (PhACs) (1, 6-8), hormones and pesticides (3), and specific contaminant removal including arsenic (9), fluoride (10), nitrate, nitrite, selenium, and radionuclides. NF can reject 80 - $95 \%$ of divalent ions such as $\mathrm{Ca}^{+2}$ and $\mathrm{Mg}^{+2}$ (3). The study showed that NF can effectively reject cephalexin, tetracycline, acetaminophen, indomethacin and amoxicillin from water (1).

\section{Significant Issues}

NF membranes are susceptible to fouling. The main matters of membranes fouling and scaling are precipita- tion of metals and salts, suspended matter and biological matter $(1,4,5)$. For example, humic and alginate acids increase fouling and reduce flux (5). In addition, solutes rejection such as amoxicillin and cephalexin and permeate flux were reduced by increasing foulants concentration (6). Therefore, feed water requires pretreatment. Permeate typically requires post-treatment for the dissolved gases removal as well as alkalinity and $\mathrm{pH}$ adjustment (1-3). The other significant issue of membrane facilities is treatment of concentrate flow before disposal (4).

\section{The Future}

The installation of NF facilities is expected to increase for water treatment in future in the world. It is due to the increase of population, urbanization of coastal and arid areas, scarcity of freshwater supplies, the increasing contamination of freshwater supplies, greater reliance on oceans, and poorer quality supplies such as brackish groundwater and treated wastewater.

\section{Conclusions}

The effectiveness of NF in water and wastewater treatment has now become one of the most reliable standard techniques to obtain good quality drinking water. Therefore, It is recommended that the Iranian water and wastewater engineering companies should study the possibility of utilizing a greater number of NF plants for water treatment, water reuse, and in particular, desalination of brackish water and specific contaminants removal.

\section{Authors' Contributions}

Mohammad Ali Zazouli and Edris Bazrafshan made extensive contributions into the review and finalization of this manuscript.

Copyright ( C) 2015, Health Promotion Research Center. This is an open-access article distributed under the terms of the Creative Commons Attribution-NonCommercial 4.0 International License (http://creativecommons.org/licenses/by-nc/4.0/) which permits copy and redistribute the material just in noncommercial usages, provided the original work is properly cited. 


\section{References}

1. Zazouli MA, Susanto H, Nasseri S, Ulbricht M. Influences of solution chemistry and polymeric natural organic matter on the removal of aquatic pharmaceutical residuals by nanofiltration. Water Res. 2009;43(13):3270-80.

2. Moarefian A, Golestani HA, Bahmanpour H. Removal of amoxicillin from wastewater by self-made Polyethersulfone membrane using nanofiltration. J Environ Health Sci Eng. 2014;12 (1):127.

3. Sanches S, Penetra A, Rodrigues A, Ferreira E, Cardoso VV, Benoliel $M J$, et al. Nanofiltration of hormones and pesticides in different real drinking water sources. Separation and Purification Technology. 2012;94:44-53.

4. Zazouli MA, Nasseri S, Ulbricht M. Fouling effects of humic and alginic acids in nanofiltration and influence of solution composition. Desalination. 2010;250(2):688-92.

5. Zazouli MA, Nasseri S, Mahvi AH, Gholami M, Mesdaghinia AR, Younesian M. Retention of humic acid from water by nanofiltration membrane and influence of solution chemistry on membrane performance. Iran J of Envir Health Sci \& Eng. 2008;5(1):11-8.
6. Zazouli MA, Ulbricht M, Nasseri S, Susanto H. Effect of hydrophilic and hydrophobic organic matter on amoxicillin and cephalexin residuals rejection from water by nanofiltration. Iran J of Envir Health Sci \& Eng. 2010;7(1):15-24.

7. Sadmani AA, Andrews RC, Bagley DM. Nanofiltration of pharmaceutically active and endocrine disrupting compounds as a function of compound interactions with DOM fractions and cations in natural water. Separation and Purification Technology. 2014;122:462-71.

8. Derakhsheshpoor R, Homayoonfal M, Akbari A, Mehrnia MR Amoxicillin separation from pharmaceutical wastewater by high permeability polysulfone nanofiltration membrane. J Environ Health Sci Eng. 2013;11(1):9.

9. Harisha RS, Hosamani KM, Keri RS, Nataraj SK, Aminabhavi TM. Arsenic removal from drinking water using thin film composite nanofiltration membrane. Desalination. 2010;252(1):75-80.

10. Nasr AB, Charcosset C, Amar RB, Walha K. Defluoridation of water by nanofiltration. Fluorine Chemistry J. 2013;150:92-7. 